\title{
Effectiveness and safety of $3.0 \%$ hydrogen peroxide patch in a double-blind randomized clinical trial
}

\author{
Jin-Kyoung Kim ${ }^{1,2}$, Hyeonjeong Go ${ }^{2}$, Jae-Hyun $\mathrm{Ahn}^{3}$, Young-Eun Lee ${ }^{1}$ \\ ${ }^{1}$ Department of Dental Hygiene, Daegu Health College, Daegu, Republic of Korea \\ ${ }^{2}$ Department of Preventive Dentistry, School of Dentistry, Kyungpook National University, Daegu, Republic of Korea \\ ${ }^{3}$ LG Household \& Health Care Research Park, Seoul, Republic of Korea
}

Objectives: As the quality of life improves, self-whitening which is safe and simple to use is becomes popular. There are a variety of bleaching agents in different concentrations on the market which can be purchased by over-the-counter (OTC) bleaching. The purpose of this study is to investigate the whitening effectiveness and safety of $3.0 \%$ hydrogen peroxide, which is a typical tooth whitening agent in Korea.

Methods: In the double-blind, randomized clinical trial, participants were recruited from March to May 2019 and 75 subjects were selected as final subjects. A whitening patch containing 3.0\% HP was applied to the labial surface of the upper 6 incisors once a day for 30- and 60 minutes using a primer and applied for 10 days. The $\Delta \mathrm{E}^{*}$ value, which determines the efficacy of whitening, was measured using Shade Eye NCC, and safety was measured using the gingival index (GI), tooth sensitivity (TS), and gingival irritation (GI).

Results: The results of applying the self-whitening agent containing primer and 3.0\% HP for 30- and 60 minutes daily for 10 days were confirmed. In both groups, a change in $\Delta \mathrm{E}^{*}$ value (Shade Eye NCC) was observed from the 5rd day, and a noticeable color change was confirmed from the 7th day. As a results of evaluating the safety, no significant changes in the gingival index (GI), tooth sensitivity (TS), and gingival irritation (GI) were observed before and after the experiment.

Conclusions: The self-whitening patch containing primer and 3.0\% hydrogen peroxide showed a change in tooth color from the 7th day when applied for 30 minutes once a day, and when applied for 60 minutes, a change in tooth color was obtained from the 5 th day. In addition, safety was satisfied in both application conditions.

Keywords: $3.0 \%$ hydrogen peroxide, effectiveness, safety

Copyright (C) 2021. Korean Academy of Preventive Dentistry. All rights reserved.

This is an Open Access article distributed under the terms of the Creative Commons Attribution Non-Commercial License (http://creativecommons.org/licenses/ by-nc/4.0) which permits unrestricted non-commercial use, distribution, and reproduction in any medium, provided the original work is properly cited. 